\title{
Preparação e Caracterização de Microesferas Poliméricas Magnéticas à Base de Estireno, Divinilbenzeno e Acetato de Vinila
}

\author{
Jacira A. Castanharo, Ivana L. Mello, Luiz C. de S. Maria, Marcos A. S. Costa \\ Laboratório de Química de Polímeros, UERJ \\ Manoel R. Silva \\ Departamento de Física e Química, UNIFEI \\ Marcia G. Oliveira \\ Divisão de Processamento e Caracterização de Materiais, INT
}

\begin{abstract}
Resumo: Microesferas poliméricas magnéticas à base de estireno (STY), divinilbenzeno (DVB), acetato de vinila (VAc) e ferro foram preparadas via polimerização em suspensão e semi-suspensão. Foram estudadas as influências da concentração de VAc adicionado na polimerização e da presença de ferro sobre as características das partículas poliméricas. Estas foram caracterizadas por espectroscopia vibracional na região do infravermelho por transformada de Fourier (FT-IR), análise termogravimétrica (TGA/DTGA), microscopia óptica por reflexão (MO), microscopia eletrônica de varredura (SEM) e magnetometria de amostra vibrante (VSM). Foram obtidas com sucesso microesferas poliméricas com propriedades magnéticas à base de estireno, divinilbenzeno e acetato de vinila. Estes materiais apresentaram bom controle morfológico esférico e partículas de ferro aglomeradas por toda a superfície da microesfera. O maior rendimento de microesferas magnéticas foi encontrado na faixa de $288 \mu \mathrm{m}$. Apresentaram também boas propriedades magnéticas (22,62 a 73,75 emu. $\left.\mathrm{g}^{-1}\right)$ com comportamento próximo de materiais superparamagnéticos e boa estabilidade térmica (444 $\left.{ }^{\circ} \mathrm{C}\right)$.
\end{abstract}

Palavras-chave: Polimerização em suspensão, terpolímero magnético, acetato de vinila, estireno, divinilbenzeno, ferro.

\section{Preparation and Characterization of Magnetic Polymeric Microspheres Based on Styrene, Divinylbenzene and Vinyl Acetate}

\begin{abstract}
Magnetic polymeric microspheres based on styrene (STY), divinylbenzene (DVB), vinyl acetate (VAc) and iron were prepared through suspension and semi-suspension polymerization. An investigation was made of the influence from the concentration of VAc added to the polymerization and the presence of iron on the properties of the polymeric particles. These particles were characterized by Fourier transform infrared spectroscopy (FTIR), thermogravimetric analysis (TGA/DTGA), reflection optical microscopy (OM), scanning electron microscopy (SEM) and vibrating sample magnetometry (VSM). Polymeric microspheres with magnetic properties based on styrene, divinylbenzene and vinyl acetate were obtained. These materials showed good control of the spheres morphology and aggregated iron particles throughout the microsphere surface. The greater yield of microspheres was found in the range of $288 \mu \mathrm{m}$. They also showed good magnetic properties (from 22.62 to $73.75 \mathrm{emu}^{-1}$ ) with superparamagnetic behavior and good thermal stability $\left(444{ }^{\circ} \mathrm{C}\right.$ ).
\end{abstract}

Keywords: Suspension polymerization, magnetic terpolymer, vinyl acetate, styrene, divinylbenzene, iron.

\section{Introdução}

Partículas poliméricas esféricas, com propriedades magnéticas, são formadas por uma matriz polimérica contendo algum material magnético ou superparamagnético inorgânico em sua composição, como $\mathrm{Fe}_{3} \mathrm{O}_{4}{ }^{[1]}, \mathrm{Fe}_{2} \mathrm{O}_{3}{ }^{[2]}$, ferritas de cobalto ${ }^{[3]}$, ferritas de manganês e zinco ${ }^{[4]}$, entres outros, disperso em sua superfície e/ou no seu interior. A matriz polimérica também possui uma composição variada, como terpolímeros à base de estireno-divinilbenzeno-ácido metacrílico (STY-DVB-MAA) ${ }^{[5]}$ ou copolímeros de estireno-metacrilato de glicidila (STY-GMA) ${ }^{[6]}$, e estireno-divinilbenzeno (STY-DVB) ${ }^{[7]}$. Além de inúmeras aplicações nos domínios da medicina, tais como diagnóstico e biologia molecular, existe um elevado potencial para aplicação dessas partículas em ciências ambientais.

As aplicações destes materiais são baseadas no fenômeno de adsorção, em que uma ou mais substâncias são retidas na superfície de um adsorvente sólido. No caso das resinas poliméricas magnéticas, o adsorvente ideal seria um com baixa porosidade, ou mesmo ausência de porosidade, de diâmetros muito pequenos, com uma grande área de superfície específica, com capacidade de fixação e seletividade que poderiam ser devidamente controlados. Outro fator importante nas resinas poliméricas magnéticas é a resposta ao campo magnético aplicado, que deve representar o estado de superparamagnetismo (o material só deve possuir magnetismo enquanto o campo lhe é aplicado, no momento em que o campo é retirado o magnetismo deve cessar). Se a magnetização não cessar, após a retirada do campo, as microesferas podem permanecer aglomeradas, dificultando o seu processo de regeneração.

Dentre as técnicas de obtenção das resinas poliméricas magnéticas, a polimerização em suspensão é a mais empregada por apresentar vantagens como a facilidade de separação, facilidade na remoção de calor, fácil controle de temperatura e, principalmente, baixos níveis de impureza ${ }^{[8]}$.

A preparação de microesferas poliméricas magnéticas à base de acetato de vinila tem sido descrita na literatura para aplicação no campo de biomedicina, especialmente na área de imobilização de enzimas ${ }^{[9,10]}$. Na área ambiental, um único trabalho foi encontrado ${ }^{[11]}$. Neste trabalho, os autores prepararam microesferas poliméricas magnéticas à base de acetato de vinila. Em seguida, três modificações químicas foram realizadas: alcoólise, reação de

Autor para correspondência: Marcos A. S. Costa, Laboratório de Química de Polímeros, Instituto de Química, Universidade do Estado do Rio de Janeiro - UERJ, Rua S. Francisco Xavier, 524, Maracanã, PHLC, 3o andar, CEP 20550-900, Rio de Janeiro, RJ, Brasil, e-mail: marcoscosta.iq.uerj@gmail.com 
epoxidação e acoplamento com ácido iminodiacético para a obtenção de grupos quelantes na superfície das microesferas poliméricas magnéticas. Estes materiais mostraram-se adequados para a adsorção de íons de cobre ${ }^{[11]}$. Entretanto, o controle da polimerização do VAc é considerada altamente difícil, pois a propagação radicalar é altamente reativa, menos estável e tende a promover reações de transferência de cadeia e reações de terminação ${ }^{[12]}$.

A literatura descreve a importância das microesferas poliméricas com propriedades magnéticas à base de acetato de vinila no campo da biomedicina, sobretudo na área de transporte enzimático e também na área ambiental. Todavia, os poucos artigos encontrados, enfatizam mais o estudo da aplicação desses materiais do que a sua síntese e caracterização ${ }^{[9,10,13]}$. Sendo assim, o objetivo deste trabalho foi estudar a síntese e a caracterização de microesferas poliméricas à base de acetato de vinila, reticulado com divinilbenzeno e contendo ferro como material magnético.

\section{Experimental}

\section{Síntese dos terpolímeros}

Os monômeros estireno (STY) (Nitriflex), divinilbenzeno (DVB) (Nitriflex) e acetato de vinila (VAc) (Sigma-Aldrich Ltda.) foram purificados conforme a literatura ${ }^{[14]}$. O iniciador peróxido de benzoíla (BPO) (Vetec Química) foi usado como recebido. O agente de suspensão utilizado foi o poli(álcool vinílico) (PVA) (Kuraray Ltda.) com grau de hidrólise de $89 \%$. O material magnético utilizado foi o ferro (Carbonyl Iron Powder OX - Basf, com tamanho médio de $4 \mu \mathrm{m}$ ). A razão fase orgânica/fase aquosa (FO:FA) foi de 1:4 para todas as reações.

\section{Semissuspensão}

Inicialmente, em um béquer de $50 \mathrm{~mL}$, os monômeros ( $0,3 \mathrm{mols})$ e o iniciador $(1 \% \mathrm{~m} / \mathrm{m})$ foram misturados, com auxílio de um bastão de vidro, durante 5 minutos em temperatura ambiente, numa capela. Em seguida, foram transferidos para um balão de três bocas de $250 \mathrm{~mL}$ e aquecidos em um banho termostatizado, durante 1 hora à temperatura de $70{ }^{\circ} \mathrm{C}$, com velocidade de agitação mecânica de $360 \mathrm{rpm}$ e em atmosfera inerte de $\mathrm{N}_{2}$. Após esta etapa, retirou-se o aquecimento e o ferro foi adicionado $(20 \% \mathrm{~m} / \mathrm{m})$. A mistura resultante constituiu a FO do sistema reacional.

\section{Suspensão convencional}

A FO (monômeros + iniciador + ferro), previamente misturada, foi adicionada num balão de 3 bocas de $500 \mathrm{~mL}$, contendo a FA, em temperatura ambiente. A FA era composta de uma solução aquosa de PVA $(0,2 \% \mathrm{~m} / \mathrm{m})$. A polimerização foi realizada em um banho termostatizado, a $80{ }^{\circ} \mathrm{C}$, em uma velocidade de agitação mecânica de $360 \mathrm{rpm}$, durante 24 horas e em atmosfera inerte de $\mathrm{N}_{2}$. O terpolímero obtido foi lavado em água e etanol diversas vezes para a retirada residual de monômeros e ferro não incorporados. Posteriormente, o material foi seco em estufa a $60{ }^{\circ} \mathrm{C}$ durante 48 horas. Logo, foi transferido para um peneirador (Retsch, modelo AS 2000 basic) onde foi separado. A faixa granulométrica que resultou na maior quantidade de microesferas $(288 \mu \mathrm{m})$ foi utilizada nas caracterizações do material.

\section{Caracterização dos materiais obtidos}

A confirmação da incorporação de VAc nas microesferas foi feita por FT-IR (Perkin Elmer, modelo Spectrum One). As condições para obtenção dos espectros foram as seguintes: ATR, resolução: $4,0 \mathrm{~cm}^{-1}$, acumulação: 4. A degradação térmica dos materiais foi verificada por TGA/DTGA (TA Instruments, modelo Q50 V6.4 Build 193),em que cerca de $10 \mathrm{mg}$ de amostra foram colocadas em uma cápsula de platina, aquecida em atmosfera de nitrogênio com uma vazão de $100 \mathrm{~mL} / \mathrm{min}$, de $50{ }^{\circ} \mathrm{C}$ a $650{ }^{\circ} \mathrm{C}$ a uma velocidade de $10{ }^{\circ} \mathrm{C} / \mathrm{min}$. As características magnéticas dos terpolímeros e do copolímero foram analisadas por VSM (Lake Shore, modelo Série 7400), no qual cerca de $0,05 \mathrm{~g}$ de amostra foram adicionados ao aparelho e o campo magnético aplicado variou de -14000 a $14000 \mathrm{G}$ e o tempo total de cada análise foi de 10 minutos, sendo os dados coletados a cada segundo. A morfologia dos materiais foi analisada por MO de reflexão (Olympus, modelo SZX 10), onde as amostras foram colocadas em uma lâmina de vidro e submetidas à ação de um feixe luminoso para observação; e por SEM-EDS (Carl Zeiss do Brasil, modelo Leo 1450 VPO) em que, previamente, as amostras foram dispersas em uma fita condutora e revestidas por uma fina camada de ouro, a fim de aumentar sua condutividade e proteger contra o aquecimento localizado. Em seguida, a amostra revestida, foi introduzida no aparelho e interagiu com elétrons secundários, em alto vácuo, sob uma tensão de aceleração de $20 \mathrm{kV}$. Os espectros de energia dispersiva de raio $\mathrm{X}$ também foram adquiridos, para confirmar a incorporação do ferro nos terpolímeros. Por sua vez, a técnica de espectrofotometria de UV-visível (Espectrofotômetro Biospectro SP-22) foi utilizada para a determinação do teor de ferro incorporado nos terpolímeros. Nesta análise, uma amostra de $0,01 \mathrm{~g}$ dos materiais [com diferentes razões molares (STY/DVB/VAc)] foi submetida à digestão com água régia durante 24 horas. Após esta etapa, as soluções foram filtradas e, por conseguinte, transferidas para balões volumétricos de $100 \mathrm{~mL}$ onde seu volume foi completado com água deionizada. Em seguida, uma alíquota foi transferida para outro balão volumétrico e o $\mathrm{pH}$ foi ajustado para a faixa de 2 a 9 pela adição de solução de acetato de sódio $2 \mathrm{M}$. Após o ajuste do pH, adicionaram-se $5 \mathrm{~mL}$ de cloridrato de hidroxilamina para manter o ferro na forma divalente e $5 \mathrm{~mL}$ de orto-fenantrolina para formação do complexo vermelho alaranjado. Em seguida, a absorbância da solução foi medida no espectrofotômetro $(\lambda=510 \mathrm{~nm})$ e a concentração de Fe foi determinada com o auxílio de uma curva padrão de absorbância vs. concentração de ferro ${ }^{[15]}$.

\section{Resultados e Discussão}

A Tabela 1 apresenta os resultados de teor de ferro incorporado e os rendimentos obtidos na síntese de STY-DVB-VAc em função da concentração de VAc adicionado nas polimerizações.

$\mathrm{O}$ efeito do ferro adicionado nas polimerizações foi verificado comparando-se os copolímeros P1 e P2 (Tabela 1). O copolímero P1, com $10 \%$ de VAc e sem material magnético, e o P2, com 10\% de VAc e com material magnético, foram sintetizados nas mesmas condições reacionais (Tabela 1). Comparando seus rendimentos de $73 \%$ e $80 \%$ respectivamente, pôde-se atribuir o aumento do rendimento da reação em $\mathrm{P} 2$ em relação a P1 ao ferro incorporado no copolímero.

A heterogeneidade das microesferas de STY-DVB-VAc foi observada pelo aspecto ótico das pérolas dos copolímeros (Figura 1). O copolímero P2 foi sintetizado com a mesma concentração de VAc adicionado (10\%) que P3 (Tabela 1). A diferença foi que em P3 uma semissuspensão foi realizada antes da adição do material magnético e da polimerização em suspensão clássica. A Figura 1a mostra o aspecto de P2 que apresentou uma heterogeneidade no tamanho das amostras. Já a Figura 1b exibe o aspecto de P3 que apresentou partículas de tamanhos mais uniformes, devido à utilização da semissuspensão. Apesar de, visualmente, não ser possível verificar os diferentes teores de ferro nos terpolímeros sem a semissuspensão (P2) e com a semissuspensão (P3), a análise de UV-visível mostrou que há diferentes concentrações de ferro nestes materiais ( $\mathrm{P} 2=8,5 \%$ 


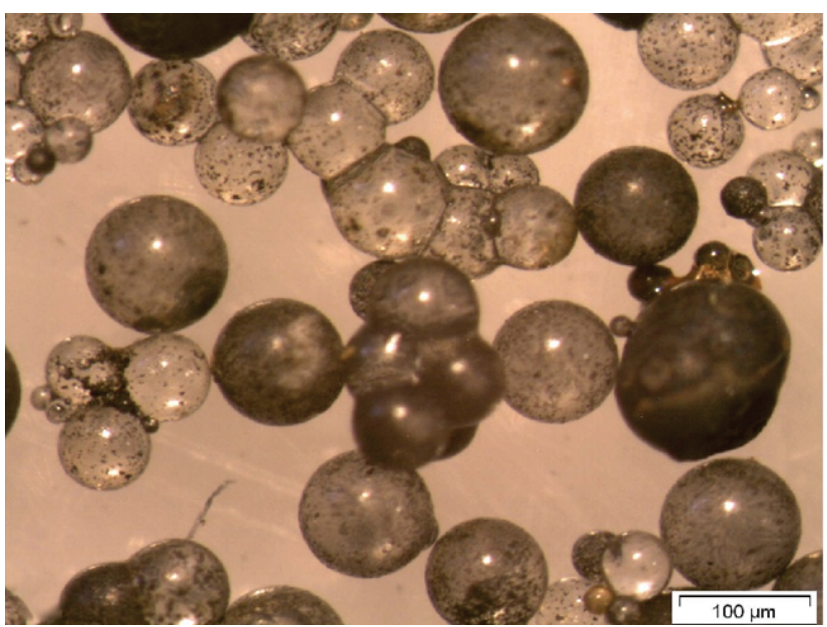

(a)

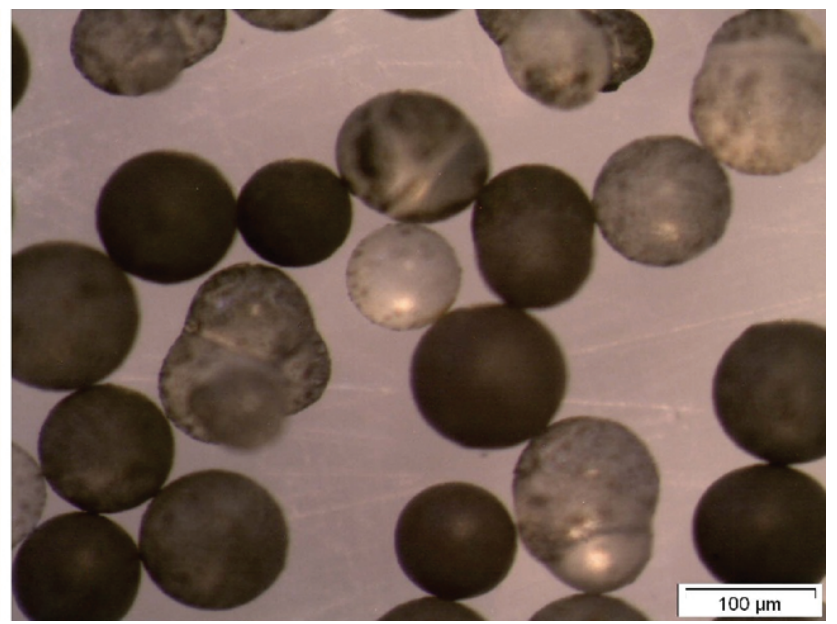

(b)

Figura 1. Micrografias de microscopia óptica dos copolímeros de STY-DVB-VAc sintetizados com 10\% de VAc: sem semissuspensão (P2)(a) e com semissuspensão (P3)(b).
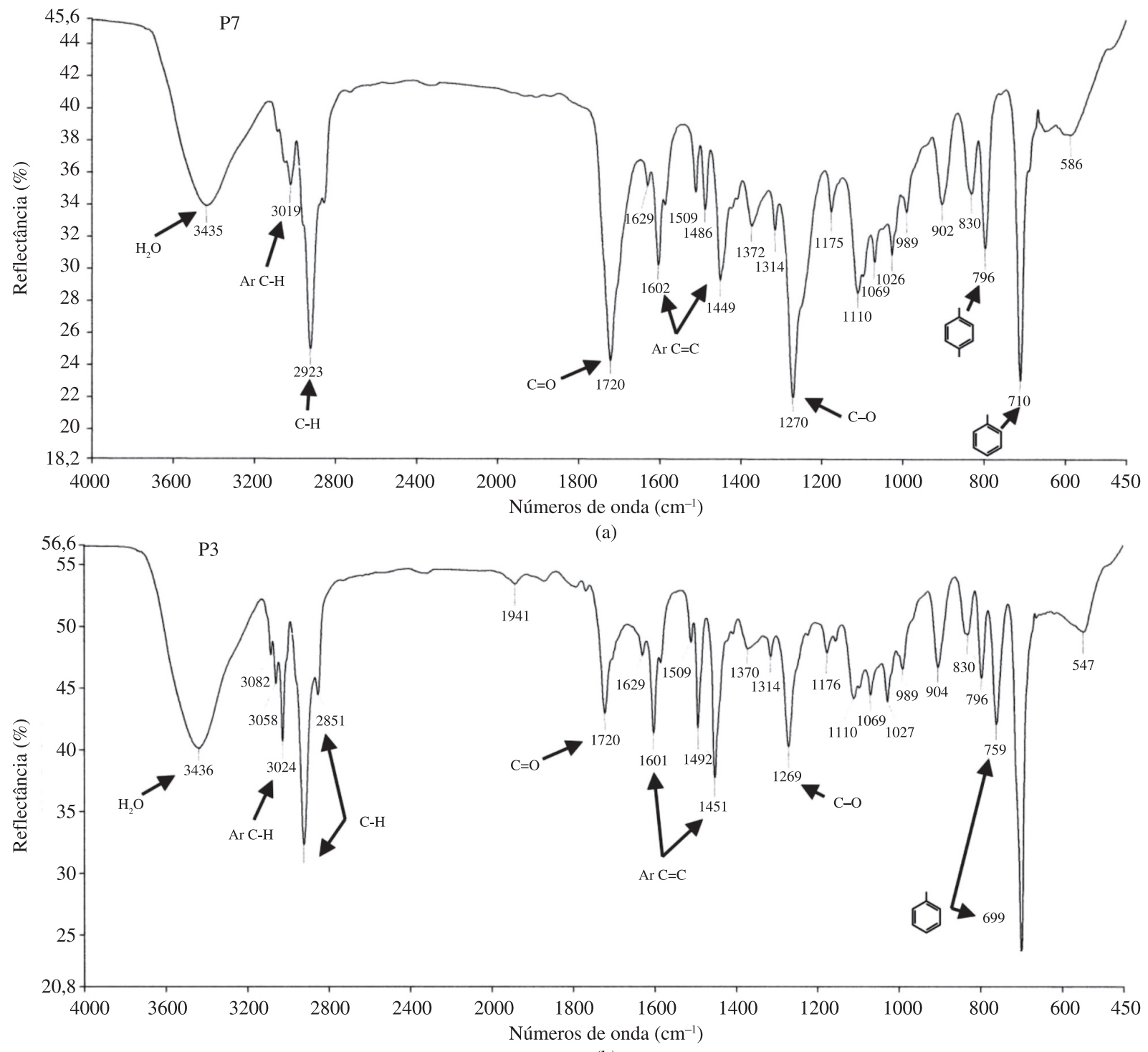

(b)

Figura 2. FT-IR dos materiais sintetizados com 90\% VAc (P7)(a) e 30\% VAc (P3)(b). 
e P3 $=21 \%$ ) demonstrando que a semissuspensão também influenciou na incorporação do ferro dos terpolímeros. Resultado semelhante foi encontrado por Costa $(2010)^{[16]} \mathrm{em}$ seus estudos com esferas poliméricas magnéticas à base de metacrilato de metila e divinilbenzeno. Com base nestes resultados, o procedimento da pré-polimerização foi adotado nas demais polimerizações.

P4, P5 e P6 (Tabela 1) mostram a influência da variação da concentração de VAc adicionado nas reações de polimerização. As concentrações de VAc variaram em 30, 50 e $70 \%$ molar, respectivamente. Em relação ao rendimento reacional, a Tabela 1 mostra que houve diminuição do rendimento da reação (62, 51 e $29 \%$ ) com o aumento do teor de VAc adicionado $(30,50$ e $70 \%$, respectivamente). Este comportamento pode ser atribuído ao fato do acetato de vinila ser um monômero polar. De acordo com a literatura ${ }^{[17]}$, alguns sistemas de copolimerização, em que um dos monômeros possui substituintes volumosos ou polares, apresentam valores inconsistentes de razões de reatividade para diferentes composições de carga de monômeros. Além disso, Silva e colaboradores (2004) $)^{[18]}$ relataram que o mecanismo de polimerização em suspensão de VAc mostra desvios consideráveis da cinética de polimerização em suspensão clássica. Por esse motivo, as conversões de monômero acima de $80 \%$ são raramente relatadas. Tal comportamento tem sido relacionado às características físicas do monômero (VAc), como a solubilidade relativamente alta em água e a alta reatividade do radical polimérico. Os autores também atribuíram o controle da velocidade reacional e da conversão máxima de monômero aos efeitos de viscosidade e/ou difusão empírica.

\section{Caracterização por FT-IR das partículas poliméricas magnéticas de STY-DVB-VAc obtidas com diferentes concentrações de VAc adicionadas na polimerização}

A Figura 2 mostra os espectros de absorção por infravermelho (FT-IR) dos copolímeros com adição de 90 e 30\% de VAc na polimerização. Os espectros indicaram bandas de absorção características da ligação de éster de $\mathrm{C}=\mathrm{O}$ do acetato de vinila em números de onda na faixa de $1700-1720 \mathrm{~cm}^{-1}$, e C-O na faixa de $1270 \mathrm{~cm}^{-1}$. Estas bandas indicam que houve a incorporação do monômero na cadeia do copolímero e também do terpolímero. Além do mais, observa-se que a intensidade dessas bandas de absorção aumentou com o aumento da concentração de VAc ao sistema de polimerização. A incorporação de STY e DVB também foi confirmada pela presença das bandas de absorção que se encontram em números de onda na faixa de $3019-3024 \mathrm{~cm}^{-1}$ atribuída à ligação $\mathrm{C}-\mathrm{H}\left(\mathrm{sp}^{2}\right)$ do tipo assimétrico aromático, C-H saturado na faixa de $2851-2923 \mathrm{~cm}^{-1} \mathrm{e}$ as bandas na faixa de $1600 \mathrm{~cm}^{-1}$ e $1449-1492 \mathrm{~cm}^{-1}$ indicam a presença do grupo fenila $(C=C)$. Já a banda em $796 \mathrm{~cm}^{-1}$ é atribuída aos benzenos dissubstituídos e as bandas $699-759 \mathrm{~cm}^{-1}$ à presença de benzenos monossubstituídos ${ }^{[19,20]}$. A banda larga na faixa de $3435 \mathrm{~cm}^{-1}$ pode ser atribuída à absorção de água nas amostras.

\section{Influência da concentração de VAc adicionada na polimerização de STY-DVB-VAc sobre a morfologia das partículas poliméricas obtidas}

A Figura 3 mostra as micrografias de microscopia eletrônica de varredura da parte externa e da parte interna das partículas poliméricas magnéticas e o mapa de composição do copolímero sintetizado com a adição de $90 \%$ de VAc na polimerização (P7). Na Figura 3a pode ser observado que o material sintetizado é esférico e apresenta pequenos aglomerados de partículas em sua superfície, Contudo, a distribuição dessas partículas não é uniforme em todas as microesferas poliméricas. Estes aglomerados são de ferro como pode ser comprovado pelo mapa de composição apresentado na Figura 3b. A Figura 3c mostra a parte interna de uma microesfera obtida com a adição de $90 \%$ de VAc na polimerização (P7). Pelo

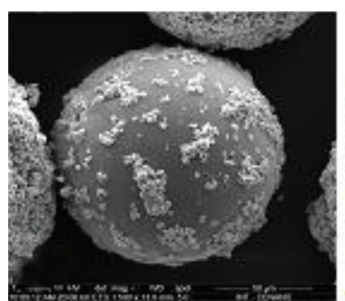

(a)

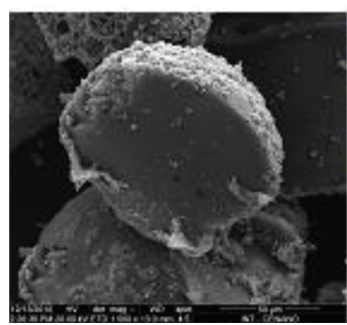

(c)

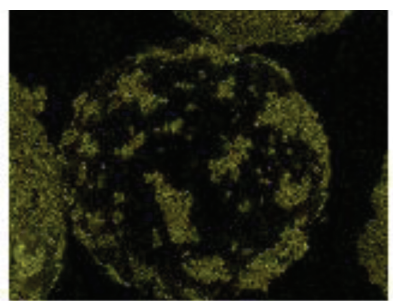

(b)

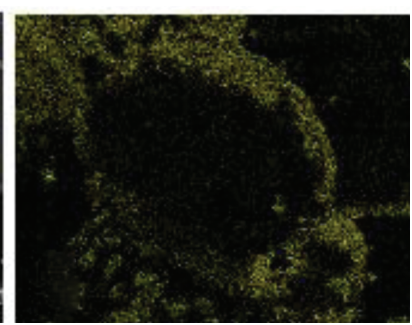

(d)
Figura 3. Micrografia de microscopia eletrônica de varredura do copolímero com $90 \%$ de VAc (P7) : Parte externa da resina com aumento de $1500 \times$ (a) e seu mapa de composição de ferro (b); Parte interna da resina com $90 \%$ de VAc (P7) com aumento de 5000× (c) e seu mapa de composição de ferro (d).

Tabela 1. Influência da concentração de VAc adicionada na síntese dos copolímeros STY-DVB-VAc sobre o teor de ferro incorporado e o rendimento da reação de polimerização.

\begin{tabular}{ccccc}
\hline Polimerização & $\begin{array}{c}\text { Razão molar STY/DVB/ } \\
\text { VAc }\end{array}$ & Ferro adicionado (\% m/v) & Ferro incorporado (\%) & Rendimento total (\%) \\
\hline P0 & $90 / 10 / 0$ & 0 & 0 & 87 \\
P1 & $80 / 10 / 10$ & 0 & 0 & 73 \\
P2 & $80 / 10 / 10$ & 20 & 8,5 & 80 \\
P3* & $80 / 10 / 10$ & 20 & 21,0 & 82 \\
P4* & $70 / 10 / 30$ & 20 & 27,9 & 62 \\
P5* & $40 / 10 / 50$ & 20 & 12,7 & 51 \\
P6* & $20 / 10 / 70$ & 20 & 14,4 & 29 \\
P7* & $0 / 10 / 90$ & 20 & 31,1 & 23 \\
P8* & $80 / 10 / 10$ & 0 & 0 & 76 \\
\hline
\end{tabular}

*Semi-suspensão de 1 hora. Condições reacionais - Quantidade de mols totais de monômeros: 0,3 mols; BPO: 1\% m.v.; PVA: 0,2\% m.v.; 360 rpm; $80{ }^{\circ} \mathrm{C}$; 24 horas. 


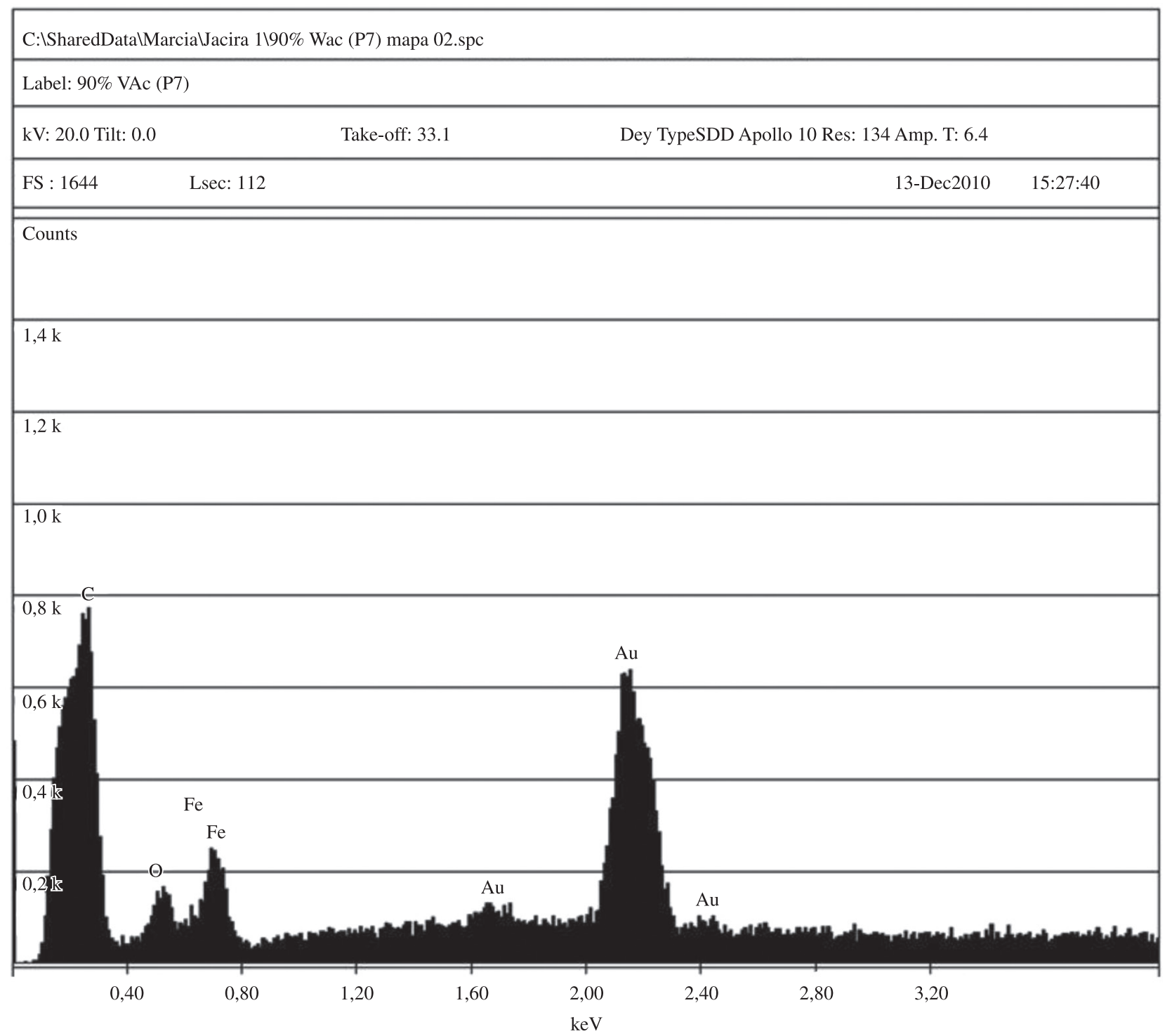

Figura 4. Espectro de energia dispersiva das partículas poliméricas magnéticas obtidas com $90 \%$ de VAc (P7).

mapa de composição mostrado na Figura 3d verifica-se que o ferro foi incorporado tanto na superfície quanto no interior do material.

A Figura 4 mostra os espectros de energia dispersiva de raio $\mathrm{X}$ (EDS) no copolímero sintetizado com 90\% de VAc (P7), onde é possível confirmar a presença dos elementos químicos oriundos da composição dos monômeros utilizados na síntese. Outrossim, é possível identificar o elemento ouro, visto que este foi o material utilizado no recobrimento das amostras. O ferro também é claramente identificado, pois é o material magnético utilizado nas sínteses. O elemento oxigênio também é observado, confirmando a incorporação do acetato de vinila nos copolímeros como a análise de FT-IR já havia mostrado.

\section{Influência da concentração de VAc adicionada na polimerização de STY-DVB-VAc sobre as propriedades magnéticas das partículas poliméricas obtidas}

A Figura 5 mostra os resultados obtidos através da curva de magnetização dos terpolímeros e do copolímero. Observa-se que a magnetização de saturação para os copolímeros sintetizados ficou na faixa de 22,62 a 73,75 emu.g ${ }^{-1}$. A literatura apresenta valores

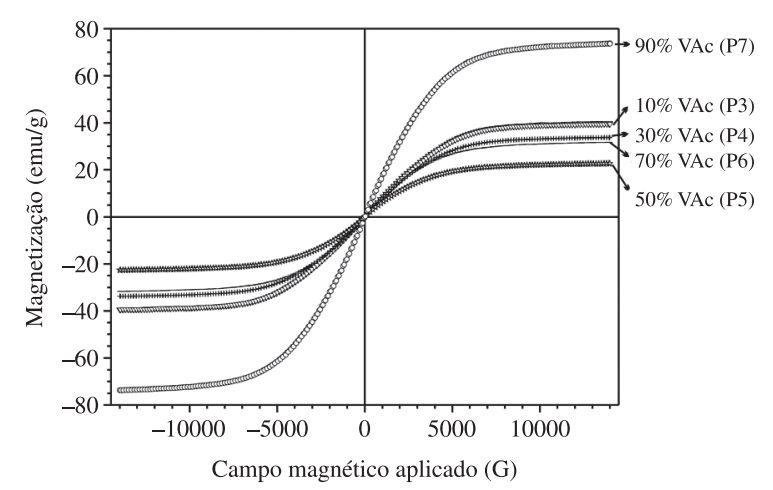

Figura 5. Curvas de magnetização das partículas poliméricas magnéticas obtidas com diferentes concentrações de VAc adicionadas na polimerização.

de magnetização de saturação destes copolímeros na faixa de 20-30 emu. $\mathrm{g}^{-1[11,21]}$. Apesar de não apresentarem ciclos de histerese, fenômeno que causa o atraso entre a densidade de fluxo magnético (B) e o campo magnético $(\mathrm{H})$, os valores de magnetização remanescente foram próximos à zero, indicando que esses materiais 
$10 \% \operatorname{VAc}(\mathrm{P} 3)$
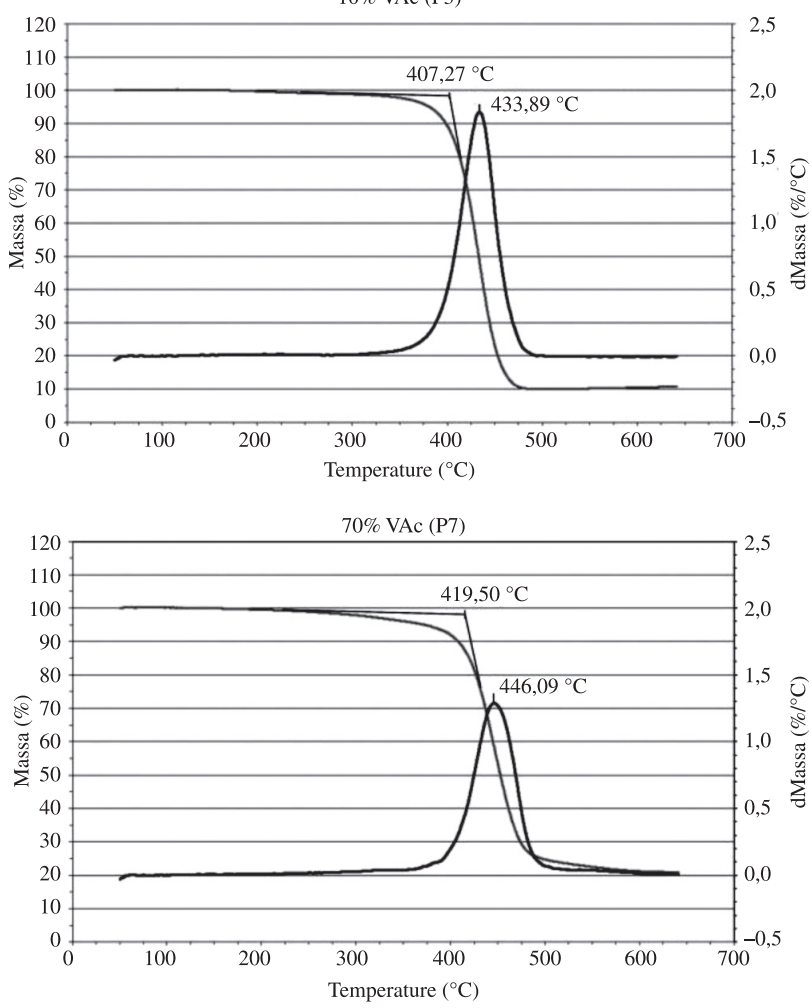

Figura 6. Curvas de TGA das partículas poliméricas sintetizadas com a adição de 10\% VAc (P3), 10 \% VAc e sem ferro (P8), 70\% VAc (P6) e 90\% VAc (P7).

$10 \%$ VAc - sem ferro (P8)
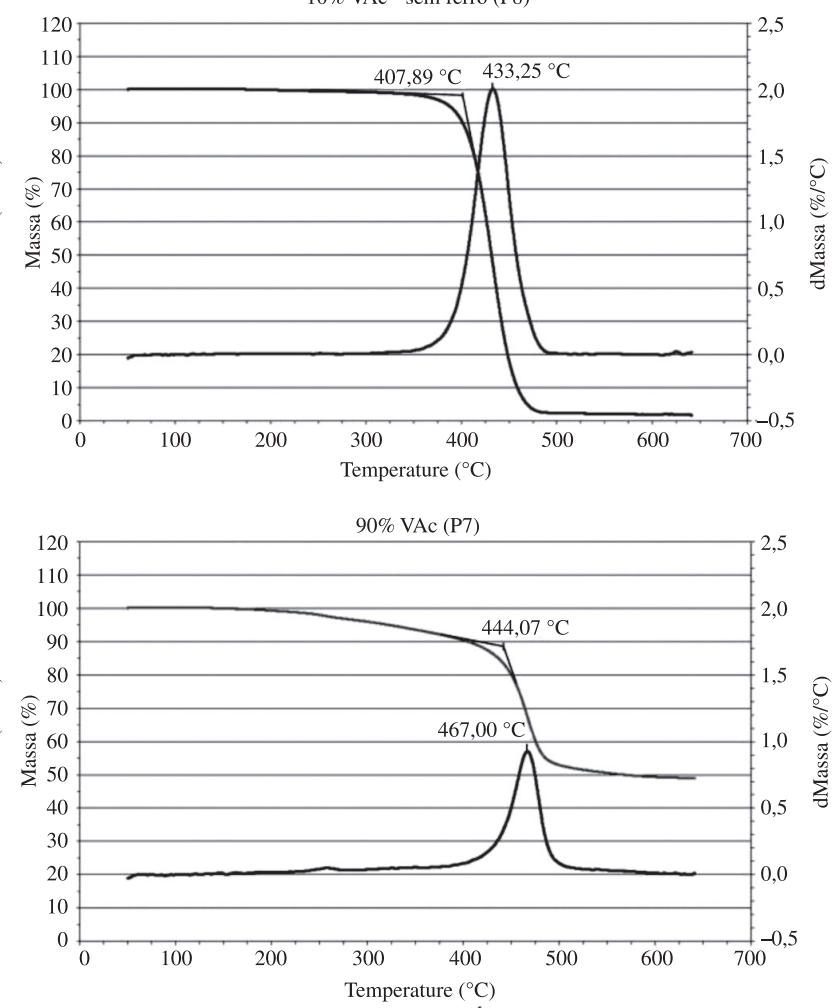

demonstram comportamento superparamagnético. O copolímero com $90 \%$ de acetato de vinila (P7), e, isento de estireno, apresentou a maior magnetização de saturação $\left(73,75\right.$ emu. $\left.\mathrm{g}^{-1}\right)$ e o maior teor de ferro incorporado $(31,1 \%)$. O copolímero com $50 \%$ de acetato de vinila (P5) apresentou a menor curva de magnetização de saturação $\left(22,62\right.$ emu. $\left.\mathrm{g}^{-1}\right)$ e o menor teor de ferro incorporado $(12,7 \%)$. Os valores dos teores de ferro incorporado nestes copolímeros são apresentados na Tabela 1 . Há evidências na literatura de que a presença de um monômero polar (metacrilato de metila) pode aumentar a afinidade do ferro pela fase orgânica, proporcionando assim a obtenção de microesferas com maiores teores de ferro ${ }^{[22]}$. Como o VAc empregado neste trabalho também é polar, o resultado esperado seria que, com o aumento do teor de acetato de vinila, aumentasse também o teor de ferro incorporado nas resinas, ou seja, a magnetização de saturação nas misturas de STY-DVB-VAc seria: P7 > P6 > P5 > P4 > P3. Entretanto, a ordem observada foi: P7 > P3 > P6 > P4 > P5. Portanto, o resultado da magnetização de saturação não acompanhou esta informação. O teor de ferro incorporado nos copolímeros também não acompanha a ordem de magnetização determinada pelas análises de VSM. Estes resultados justificam-se pela forma heterogênea da incorporação do ferro nas microesferas. Se a distribuição de ferro no copolímero não for uniforme, encontram-se pontos com diferentes quantidades de ferro mesmo que a quantidade de ferro adicionada seja a mesma em todas as sínteses $(20 \% \mathrm{~m} / \mathrm{m})$. Esse resultado corrobora com os resultados mostrados nas micrografias da Figura 3.

\section{Influência da concentração de VAc adicionada na polimerização de STY-DVB-VAC sobre a estabilidade térmica das partículas poliméricas magnéticas obtidas}

Conforme observado na Figura 6, todos os copolímeros apresentaram uma única zona térmica de perda de massa, relativa à decomposição da matriz polimérica, e um único pico de DTGA relacionado a este estágio de decomposição. A decomposição de todas as amostras começou em temperaturas acima de $200{ }^{\circ} \mathrm{C}$ e terminou antes dos $600{ }^{\circ} \mathrm{C}$. Comparando-se as amostras P3, P6 e P7 (VAc $=10,70$ e $90 \%$, respectivamente), verifica-se que o aumento do teor de VAc influenciou, consideravelmente, na temperatura de degradação. A $\mathrm{T}_{\text {onset }}$ destes materiais foi de 407,419 e $444{ }^{\circ} \mathrm{C}$, respectivamente (Figura 6). É provável que o teor de VAc influencie na faixa de degradação do material polimérico.

A margem de erro das análises de TGA é de mais ou menos $4{ }^{\circ} \mathrm{C}$, então comparando P3 (10\% de VAc e com Fe) e P8 (10\% de VAc e sem $\mathrm{Fe}$ ), pode-se verificar que a introdução do material magnético não influenciou na perda de massa, pois ambas possuem $\mathrm{T}_{\text {onset }} \mathrm{em}$ torno de $407^{\circ} \mathrm{C}$. Ademais, as formas das curvas de TG para essas amostras são semelhantes, mostrando a superposição dos processos.

\section{Conclusões}

Foram obtidas com sucesso microesferas poliméricas com propriedades magnéticas à base de estireno, divinilbenzeno e acetato de vinila. Estes materiais apresentaram bom controle morfológico esférico, com maior rendimento na faixa de 288-75 $\mu \mathrm{m}$. Também revelaram boas propriedades magnéticas $\left(73,75 \mathrm{emu}^{-1}\right)$ e boa estabilidade térmica $\left(444{ }^{\circ} \mathrm{C}\right)$. $\mathrm{O}$ emprego da semissuspensão melhorou a uniformidade de tamanhos das partículas poliméricas magnéticas e o teor de ferro incorporado. O copolímero com $90 \%$ de VAc apresentou a maior concentração de ferro incorporado $(31,1 \%)$, apesar do comportamento não linear na relação da concentração de VAc e o teor de ferro incorporado.

\section{Agradecimentos}

Os autores agradecem ao Conselho Nacional de Desenvolvimento Científico e Tecnológico (CNPq) pela bolsa de mestrado (Proc. 555252/2009-4) concedida a Jacira A. Castanharo e à FAPERJ pelo 
apoio financeiro; à Nitriflex pela doação dos monômeros; à M.Sc. Sheyla Santana de Carvalho do Instituto Nacional de Tecnologia (INT) pelas análises de SEM.

\section{Referências Bibliográficas}

1. Wang, J.; Deng, T. \& Dai Y. - J. Alloys Compd., 390, p.127 (2005). http://dx.doi.org/10.1016/j.jallcom.2004.06.101

2. Sun, Y.; Ma, M.; Zhang, Y. \& Gu, N. - Colloids Surf. A, 245, p.15 (2004). http://dx.doi.org/10.1016/j.colsurfa.2004.05.009

3. Rajan, G. S.; Stromeyer, S. L.; Mauritz, K. A. \& Miao, G. - J. Magn. Magn. Mater., 299, p.211 (2006). http://dx.doi.org/10.1016/j. jmmm.2005.04.004

4. Mathur, R.; Sharmad, R.; Vadera, S. R.; Gupta, S. R.; Sharma, B. B. \& Kumar, N. - Nanostruct. Mater., 11, p.677 (1999). http://dx.doi. org/10.1016/S0965-9773(99)00356-6

5. Kong, S.; Cheng, J.; Liu, Y.; Wen, X.; Pi, P. \& Yang, Z. - Cent. Eur. J. Chem., 6, p.627 (2008). http://dx.doi.org/10.2478/s11532-008-0055-y

6. Maeda, M.; Kuroda, C. S.; Shimura, T.; Tada, M. \& Abea, M. - J. Appl. Phys., 99, p.08H103 (2006).

7. Lee, Y.; Rho, J. \& Jung, B. - J. Appl. Polym. Sci., 89, p.1058 (2003). http://dx.doi.org/10.1002/app.12250

8. Machado, F.; Lima E. L. \& Pinto J. C. - Polímeros, 17, p.166 (2007). http://dx.doi.org/10.1590/S0104-14282007000200016

9. Bozhinova, D.; Galunsky, B.; Yueping, G.; Franzreb, M.; Koster, R. \& Kashe, V. - Biotechnol. Lett., 26, p.343 (2004). PMid:15055773. http:// dx.doi.org/10.1023/B:BILE.0000015471.18648.40

10. Guo, Z.; Bai, S. \& Sun, N. Y. - Enzyme Microb. Technol., 32, p.776 (2003) http://dx.doi.org/10.1016/S0141-0229(03)00051-6

11. Tseng, J.; Chang, C.; Chen, Y. \& Chiang, P. - Colloids Surf. A, 295, p.209 (2007). http://dx.doi.org/10.1016/j.colsurfa.2006.09.001
12. Wakioka, M.; Baek, K. Y.; Ando, T.; Kamigaito, E. \& Sawamoto, M. - Macromolecules, 35, p.330 (2002). http://dx.doi.org/10.1021/ $\mathrm{ma} 0115444$

13. Chen, M.; Lin, Z. \& Qian, H. - Chin. Chem.. Lett., 19, p.1495 (2008). http://dx.doi.org/10.1016/j.cclet.2008.09.050

14. Mano, E. B.; Dias, M. L. \& Oliveira, C. M. - "Química experimental de polímeros", Editora Edgard Blücher, Rio de Janeiro (2004).

15. Vogel, A. I. - "Análise química quantitativa”, Editora LTC, Rio de Janeiro (1992),

16. Costa, C. N. - "Síntese e Caracterização de copolímeros à base de poli(metacrilato de metila) e divinilbenzeno com propriedades magnéticas", Dissertação de Mestrado, Universidade do Estado do Rio de Janeiro, Brasil (2010).

17. Coutinho, F. M. B. \& Oliveira, C. M. - "Reações de polimerização em cadeia - Mecanismo e Cinética", Editora Interciência, Rio de Janeiro (2006).

18. Silva, F.; Lima, E. L. \& Pinto, J. C. - Ind. Eng. Chem. Res., 43, p.7324 (2004). http://dx.doi.org/10.1021/ie0342681

19. Zipp, E. M. \& Kabalka, G. W. - Carbon, 34, p.1539(1996). http:// dx.doi.org/10.1016/S0008-6223(96)00101-7

20. Sanagi, M.; Naim, A. A.; Hussain, A.; Siregar, S. H.; Sarjadi, M. S. \& Aziz, N. A. - Development and Application of New Modified Poly(styrene-divinylbenzene) Adsorbents and Chromatography Stationary Phases, Vol. 1: PS-DVB heptadecyl ketone, chloromethyl PS-DVB, and octadecoxymethyl PS-DVB, End of Project Report, Technological University of Malaysia (2006). Disponível em: <http:// eprints.utm.my/2716/1/74091.pdf>. Acesso em: 07 fev. 2011.

21. Chen, Y.; Liu, Y.; Lin, R. \& Yen, F. - J. Appl. Polym. Sci., 108, p.583 (2008). http://dx.doi.org/10.1002/app.27644

22. Santa-Maria, L. C.; Costa, M. A. S.; Santos, F. A. M.; Wang, S. H. \& Silva, M. R. - Mater. Lett., 60, p.270 (2006).

Enviado: $10 / 02 / 11$

Reenviado: 16/08/11

Aceito: 13/09/11 